\title{
The Effects of Electronic Service Context on Customer's Quality Perception
}

\author{
Wiem Jenzri Sfar \\ Faculty of Economics and Management in Sfax - Tunisia
}

\begin{abstract}
This analytical paper highlights how the customer's quality perception could be deeply impacted by the integration of electronic supply service additionally to other distribution channels. Based on an analysis of the changes the electronic context has induced, it emphasizes the modifications of the traditional characteristics of the service offering context and the reconsideration of the usual bases of the quality assessment.
\end{abstract}

Keywords: perceived quality, electronic context, evaluation, service.

\section{Introduction}

It is clear that many merchant Web sites are not to match consumer's requirements or expectations although the challenge of mastering the effects of using the Internet as a marketing and relational medium on the consumer is vital for professionals (Sabadie and Vernette, 2003). This leads us to believe, on the side of the manager, that the parallel between the adoption of the internet and the mastery of its fallout on the consumer is not adequately developed, which negatively affects the effectiveness of quality management service. Furthermore, when it comes to ensuring the profitability and development of the service offering on line, on the one hand, and being up to the expectations of the consumer through the website, other the hand, the fear of the perceived quality of electronic service proves to be crucial, hence, the need to explore how the Internet influences and even alters the consumer perceptions about the quality of service delivered.

The purpose of this paper is to show analytically how the quality perceived by the consumer is affected by the change of context and, in particular, the support for the provision of service. In this framework, we start from the observation that the perceived quality of service is altered as a result of this change and, therefore, a "redefinition" of the concept of perceived quality and the basis of its evaluation will be on display in the first part, and an analysis of the impact of this change on the perception of service quality will be established in the second part.

\section{Perceived Quality of Traditional Service}

The expansion of the adoption of Internet as a commercial and relational tool has imposed on the researcher a review of some classical concepts initially introduced in a traditional context (shop, agency ...) as well as the revision of definitions referring to it, which is the case of the concept of perceived quality. Moreover, since the development of the service sector, researchers and managers have noticed the features relating to the offer on the intangibility of the service and the degree of client involvement in the process of servuction. Thereby, post clearance control of the quality of service has revealed ineffective. A service quality that researchers regard as an abstract and vague concept, which affects both the assessment and the modeling (Parasuraman et al, 1985). In the lack of

Copyright (C) 2012 Wiem Jenzri Sfar. This is an open access article distributed under the Creative Commons Attribution License unported 3.0, which permits unrestricted use, distribution, and reproduction in any medium, provided that original work is properly cited. Contact author: Wiem Jenzri Sfar E-mail: jenz.wiem@gmail.com 
objective measures, the resort to assess the quality of service based on consumer perceptions has been proposed by many researchers.

The perceived quality is a concept that puts forward the judgments and perceptions of the customer who has the final decision to purchase and whose measure is based on the paradigm of non-confirmation of expectations. Its basic principle is summarized in that it defines perceived quality as a difference or comparison between the customer perceptions (perceived performance) and his expectations (standard pre-set) (Oliver, 1977).

The perceived quality of traditional service can be defined as "an overall assessment, or a standpoint, regarding the high standard of a service" (Parasuraman et al., 1988) or even as a cognitive process referring to the difference between the expectations and perceptions of consumers in the field of service (Asubonteng et al, 1996).

In the frame of this section, we have opted for a definition summarizing the last two when we consider that the concept of quality of service can be defined as the decision of the client which is based on all service dimensions and generated by a cognitive process. We explain the concept of "service dimensions" at different angles in the following.

The perceived quality of service in an interpersonal context has a rich literature that gives rise to two sets of conceptual models focused on the evaluation of this concept by the consumer: A first set of models based on the structure of the service and a second set based on service attributes. The first set can be amounted to two main streams:

- The Nordic trend (Grönroos, 1982) identifies three dimensions of perceived quality of service: the functional quality (the way the service is offered), the technical quality (the content of the service offering) and the company image as perceived by the consumer.
- The French trend (Eiglier and Langeard, 1987) proposes three further dimensions: the elements of servuction (personal contact and physical support), the output of the basic service (service ability to meet customer expectations), the process itself (variables reflecting interactions between the operative staff and the client).

The approach of the second set is based on the observation that a number of service attributes reflecting the most appropriate criteria for the assessment of the consumer defines the quality of service. The model put forward by Parasuraman, Zeithaml and Berry (1985) prevails in a virtually absolute way: As a matter of fact, the quality of service is based on the gap between consumer expectations regarding service performance and the service actually received. This model has given rise to the scale measuring the perceived quality of traditional service SERVQUAL (Parasuraman et al, 1985) made up of five main dimensions: The tangibility, representing the physical space, personnel, equipment and documents(1), the reliability, reflecting the ability to perform the promised service in a safe and accurate way (2),the responsiveness, defined as the willingness to help customers by providing a fast and adequate service (3),the empathy, being the consideration and individual attention paid to each client in the business (4),the insurance reflecting the courtesy and helpfulness of staff and their ability to inspire confidence (5).

\section{Perceived Quality of Electronic Service}

The fast spreading of the internet has marked the transition from one interpersonal context in which a slight damage might sometimes be made up for by a simple apology accompanied by a smile from the staff of the company at a time when no human contact is indispensable between the company and its client, in other terms, the transition from a customer / man interaction to a customer / machine one. The implementation of a dynamic and interactive relationship based on technology is upsetting the flow conditions 
of the transaction and, therefore, altering the quality perceived by the consumer (Dabholkar, 2000). A redefinition, which seems to be the most simple and the most concise of the perceived quality of electronic service was proposed by Zeithaml, Parasuraman and Malhotra (2002): "The extent according to which a website facilitates the effective and efficient storage, purchase and delivery of products or services". Bressolles and Durrieu (2006) admit that the simultaneous integration of pre-and postservice elements of experience in the assessment of quality provides useful information on the transactional nature of this quality when it comes to virtual context.

There is no doubt that an adaptation or even a calling into question of the dimensions of perceived quality in traditional service is needed in a context where man is substituted by a machine. Moreover, this raises some fundamental issues, namely the practical difficulty of this adaptation and the need to introduce some dimensions suitable for the context of electronic service. For example, how the insurance dimension, which reflects the courtesy of employees and their ability to inspire confidence, will be measured when the customer interacts with a machine? Or, what role can the layout of the website and its usability (items that are not obviously part of the SERVQUAL scale) play in the perception of electronic service quality? Hence, the obligation to adapt the dimensions of SERVQUAL and integrate new dimensions specific to e-commerce justify the devising of new tools for measuring the perceived quality of electronic service, something which is still at its early stage. We note from the marketing literature the six major studies that have proposed measuring scales for the perceived quality of electronic service: SiteQual (Yoo and Donthu, 2001), eTailQ (Wolfinbarger and Gilly, 2003), WebQual (Barnes and Vidgen, 2003 ), e-ReS-Qual (Parasuraman et al, 2005), ES-Qual (Parasuraman et al, 2005), NetQual (Bressolles and Durrieu 2006) (Appendix 1).
These scales have largely contributed to the evolution of research on measuring electronic service quality by the consumer. However, they still remain few and fairly debatable. The main criticisms can be summarized as follows:

- Most studies on these scales relate to convenience samples, mostly consumer and student panels, instead of online shoppers of the sites in question.

- Some studies - including WebQual NetQual - do not cover the entire purchasing process online where the act of performing the whole purchasing process is not a requisite to answer all the questions, which excludes some elements of the life cycle of electronic service ranging from browsing for information to the stage of after sales service: These first two limitations call into question the internal and external validity of the results of some studies.

- The measurements obtained are considered particularly general because they do not relate to a limited number of web sites, which generates too generalized assessments of electronic service quality by the consumer. Moreover, these scales, excepting NetQual, were devised and tested in a North American environment which pervades the dimensions identified by a functional aspect that characterizes it.

In summary, it is indisputable that the change of the service experience due to the changing environment of purchase has legitimized the revision of the concept of perceived quality of service and the reconstruction of appropriate metrics for its measurement in a depersonalized and automated context, but the question of the impact of the characteristics of this context on the perception of quality remains. Further still, it is necessary to synthesize and analyze the levels of perceived quality where this impact occurs. 


\section{A Perceived Quality of Service Affected by Electronic Environment ... At What Level? How?}

Certainly, the electronic consumption context influences the perception of quality by the consumer, but for those who wish to get a deeper analytical vision, this finding turns out to be insufficient, hence, the importance of a further investigation into this phenomenon. From the outset, we postulate that the perceived quality of service is affected at the bases of judgment and evaluation of the consumer as to the quality of service: So what is the effect of the mechanisms in use to support the transition from a perceived traditional quality to another electronic one on the judging system of the consumer.

\section{From Tangibility to Virtuality}

The characteristic of intangibility which naturally distinguishes service offer is accentuated in the context of electronic service where the inviolability of the offer is accompanied by the virtualization of supply space. Indeed, digital technology provides a virtual environment where digital information is the only form that the service can take (or even the product) and consequently substitutes material and paper flows for digital flows which mark the virtualization of the sales area. In a traditional retail environment, the client builds his judgment on the quality of service taking into consideration, among other elements, physical data are inverted by means of telling the service provider to ensure the best quality service. In the same respect, these data are highlighted by the SERVQUAL scale (Parasuraman et al, 1988) in the "tangibility" dimension which reflects the physical appearance of the premises, equipment and personnel. But the Web medium does not enable in any way the understanding of the level of service quality from an assessment of resources that are immediately visible and undertaken by the service provider as opposed to a traditional retail space. For example, the perception of the quality of banking services by the client is based in part on material elements he sees, such as the immediate appearance of a branch and the courtesy of the bank employees. By cons, on the website of the same bank, the evaluation of the physical items by the customer is limited to the characteristics of the digital interface of the virtual bank branch. Indeed, Bressolles and Durrieu (2006) agree that the "tangibility" dimension defined by the SERVQUAL scale would correspond, in a virtual context, to "design and graphic style of the site," which refers to the wealth of the presentation of the virtual sales area, as displayed prominently by its formal characteristics (colors, images, graphics, animation ...) and which help create the atmosphere of the virtual retail space.

It would be pertinent to note at this level that the characteristics of the sales service area represent, for its service provider, a prevailing element in the perception of quality of service by the customer (Rust and Oliver , 1994). However, the control of the conditions of this area of service varies with the sales media involved. Indeed, when it refers to the context of electronic service, the service provider loses a considerable margin of control and the mastery of sales and distribution space becomes much less obvious compared to the context of traditional service, so the customer comes into contact with the service, he decides the time and place by logging on to the website when he wishes, he orders or consumes the service under the conditions he chooses. This scope of freedom granted to the customer through the virtualization of the sales area which is outside the service provider part makes it more difficult to optimize the conditions of sale by the latter, which causes a partial loss of control over the level of perceived quality of electronic service.

\section{From the Human to the Machine}

\section{The Dehumanization of the Service Relationship}

It is undeniable that the contact staff is a major component in the overall assessment system of the quality of service where the level of the latter is conditioned, firstly, by the performance of the employee and, secondly, the level of satisfaction that the 
customer can derive in his relationship with the contact staff. Thus, a personalized service relationship with the client often generates relational satisfaction on which the service provider relies, among other things, to improve the quality of service offered.

When it comes to electronic offering environment, the human dimension with the ensuing benefits - including empathy, listening, customization of the offer - is totally disabled. Further still, the very nature of the service relationship is affected: the client moves from one relationship where the main counterpart is an employee to another where he is facing a machine. As a result, the service relationship between the client and the service provider undergoes dehumanization because of the substitution of human interaction with a human-computer interaction (Philippe, 1994). Such a relationship being dehumanized and dematerialized following the integration of electronic sales support upsets, on its part, the basis for assessing the quality of service endowed with human touch traditionally perceived by the customer, particularly empathy (which is related to the consideration and individual attention paid by the employee to each client) and insurance (which refers to the courtesy and helpfulness of the employee and his ability to inspire confidence). By analogy, in an electronic environment, both human dimensions have been adapted by Barnes and Vidgen (2003) as part of the adaptation of the SERVQUAL scale in the provision of online service and have been replaced by the dimensions, quality of the interactivity of the Web site and the degree of customization of electronic commerce, in so far as the latter two dimensions provide the cyberconsumer with appropriate responses and increases the degree of flexibility in the composition of electronic service.

It should be noted that the contribution of IT in an attempt to bridge the human gap in the e-commerce exchange, in general, is remarkable because the electronic agents and interactive agents, which are custom software and a learner acting on behalf of an individual, are among the technical proposals considered by the managers. However, their application remains limited and their perception may be directed to a form of intrusion felt by the cyberconsumer.

In summary, the passage from a human relationship to a technologically mediated relationship marks the shift from human phenomena into digital phenomena: empathy and assurance of humans being replaced by the quality of interactivity and personalization of the Web site. These last two reflect the ability of the client to shape the service that best suits their needs, change the content and form of the mediated environment in real time while maintaining a privileged relationship with the service provider.

\section{The Standardization of Service Delivery}

The ability to listen, the capacity for empathy and the quality of training received by the employee are all critical elements of the performance level of traditional service delivery. The task of the employee in contact consists mainly in a function of interpretation which amounts to treating the needs expressed by the client in everyday language and translate them into appropriate technical language. However, in the interpersonal context, the counterpart is an employee who is not necessarily the same at each visit of the customer. This causes a variation in the performance of the service which operates in parallel with the variability of the employee in contact. Moreover, the performance of the service is crucial in the perception of quality of service to the customer which entails instability in the level of quality perceived by the consumer in traditional sales. In contrast, the Web context is marked by a system of remote electronic servuction where the service is delivered by the technological support without any direct physical intervention of the employee. In fact, the service delivered by a Web site is characterized by a standardization of questions and a preconception of answers that reduce the room for manoeuvre left to the consumer and guarantee a stable standard of 
performance and service delivery (Tournaments, 1999). Hence, we assume that the constant level of quality of delivered service - and therefore the assessment of this quality by the consumer - varies with the nature of the party issuing it; This is a level of quality that will be as variable as the change in contact personnel in the case of an interpersonal context, and a standardized and fairly stable level of quality in the case of an exchange via a website. To support this, it should be noted that the reactivity - a dimension reflecting the desire to help the customer by providing a fast and responsive service- in a traditional context is variable as it depends on the competence and quality of service of the employee. By cons, in an electronic environment, this reactivity could lead to "rapid process" that depends on the program integrated into the website interface that supports the processing and delivery of service in the same way for each type of application (Yoo and Donthu, 2003). Consequently, the speed of the process remains unchanged for each type of service.

It should be noted that if the technological support helps stabilize the level of service quality through standardized electronic delivery, it certainly does not guarantee the function of interpretation - provided by staff in contact - that identifies the best customer needs and thus better satisfy him.

\section{From Traditional Information to Digital Information}

It should be noted that the preparation phase of the purchase (evaluation of alternatives) and that of the actual purchase can take place in two different contexts. In other words, the consumer may bear an intention to purchase in a traditional context, which was based on evaluations and preferences incorporated in an electronic environment. Thus, a prepurchase phase of research for information carried by the customer on the Internet could change the amount and type of information to be processed in the traditional context. This observation can be viewed at an angle where the cognitive effort made by the customer reflects his behavior (Filser, 1996) as follows:

- If the consumer has not made a prepurchase phase of research on the Internet, he will have to make the selection, the sorting, the matching and the evaluation of offers on the traditional point of sale, which requires a considerable cognitive effort.

- If not, in case a fairly conclusive research for information and a rational assessment have taken place on the Internet, the consumer will use a low cognitive effort for any additional or more specific information on the traditional point of sale.

Moreover, consumers have uneven information needs that are faced with a constant and often inappropriate level of information available in a traditional shopping environment. Therefore, the consumer is found with a large volume of information which does not necessarily meet his needs but exceeds his processing capacity and this is where heuristics interfere to facilitate the formation of preferences. By cons, when it comes to the electronic environment, the processing of information is systematized through the interactive tools of this technology and which support the selection, the sorting and the matching of information, as an integral part of the mental effort that should be produced by the client. Under these conditions and with Internet technology, the most central criteria of consumer choice are more distinct and preferences are clearer after the evaluation of alternative service offering (Volle, 2000). Consequently, the electronic environment allows the consumer to process information in an analytical, more rational and systematic manner compared to the traditional context in which information processing is rather heuristic, and in some cases, can even be emotional.

These findings regarding the specificity of information processing, when it comes to support electronic sales, affect the evaluation of the customer service at two levels: The first level refers to information available on the Web service. 
Let's bear in mind that, for an on-line service purchase, multimedia information is the only form that take the offer, the marketing and advertising message, the sales space, the commercial counterpart... As a result, multimedia information is the sole source for evaluating electronic service unlike the traditional one, accentuating the need for e-customer clarity and more accurate information to be tailored to his needs. In the same respect, Bressolles and Durrieu (2006) have identified and selected a dimension that reflects the perception of cyber-client information to the media and they have called "quality and quantity of information presented on the site "as part of the construction of a measuring scale for electronic service quality NetQual.

The second level relates to the contributions of interactive tools offered by the electronic media. Indeed, the systematization and streamlining of multimedia information processing made possible by interactive tools of the electronic medium lead to an assessment of the quality of service more reliable than one based exclusively on the cognitive abilities of the client in a traditional context.

\section{Perception of Online Service Purchase Risk}

The characteristic of intangibility which distinguishes the service offering enhances the perception of risk among consumers especially during the pre-purchase stage, the feeling of risk is in turn reinforced by the electronic environment of online services (and Sabadie Vernette, 2003). Indeed, interpersonal relations and human contact turn out to be critical in the restraint of the sense of risk and the building of confidence in a traditional shopping environment are eliminated by the environment of electronic sales service: the purchase on the Internet channel reinforces the sense of uncertainty among consumers fearing a possible negative result of a delivered service incompatible with the one ordered. Indeed, on the website, the cyberconsumer needs more clear, accurate and credible information in order to make up for the employee's place and his role of insurance in the traditional context. This need could be partly met by graphics features and interactive capabilities of the website in order to shape the content and form of information in an appropriate manner in relation to expectations and motivations of the cyberconsumer. However, we recognize that the electronic environment of sales encourages the installation of a sense of uncertainty and perplexity in the customer as to the reliability of sales tools and payment security implemented by the service provider. In addition, he is also concerned about the appearance of the website privacy on which he plans to make probably his purchase (Sabadie and Vernet, 2003).

If we join two central findings: the first is that the cyberconsumer sees his risk assessment "stiffened" in an electronic environment (Sabadie and Vernet, 2003), and the second is that the relationship between the risk that the client perceives, following the purchase of a service and the quality of the latter is negative (Cases, 2002), we deduce that the same service undergoes quality deterioration just by shifting from a traditional to an electronic environment. Therefore, the assessment of service quality becomes "stiffer" and "more rigid" in that the client himself becomes tougher and more demanding in terms of data privacy, security of payment tools and intelligibility of the application via the website despite the efforts of service providers: Indeed, the latter, meanwhile, are implementing policies and programs for secure payments and protection of personal data to ease the sense of risk in the cyberconsumer and well build trust in order to improve the quality of online service (Cases, 2002).

Moreover, the new scales for measuring electronic service quality by the customer (NetQual, WebQual, SiteQual ...) are two dimensions that will reappear in the same sense as our analysis: First, "the security and compliance of privacy "which refers to the protection of personal data, the risk of fraud and financial losses. The second dimension, "reliability and compliance", 
reflects the ability of the on-line service to keep its promises and meet the terms of trade.

\section{Summary of Theoretical Contributions}

We highlighted, in what has preceded, the different levels where changes or even upheavals arise after the passage of the context from the sale of a tangible and interpersonal status to a virtual state, technologically mediated. Our analysis focuses on the impact affecting the perceived quality among consumers and particularly the basic foundations for assessing the quality of service. On the one hand, this passage entails the virtualization of retail space, in other words, the dematerialization of concrete evidence on which the customer traditionally relies to assess the quality of service; this results in the substitution of classical measurement bases with new appropriate bases, specific to the electronic environment. Indeed, the "tangibility" of the place of sale has its parallel in "the design and graphic style of the website" that reflect, virtually, the presentation and characteristics of the retail space. It follows that in the context of electronic sales; the service provider notices his control of the sales area of service, which partly represents the control of the level of service quality, being limited at the benefit of a margin of freedom granted to the client.

On the other hand, the substitution of the human counterpart in the service relationship with the machine generates, in terms of assessing the quality of service delivered, a level of performance more stable and standardized, unlike the interpersonal relationship where this level is as irregular and fluctuating as the variation of the employee in contact. Moreover, the nature of the service relationship is dehumanized, which directly affects the quality assessment by the customer. The latter is now based on the characteristics of interactivity and personalization of the website at the expense of human characteristics totally abolished with the shift to the context of electronic sales.
In addition, the quality of information processing plays a major role in the evaluation of service by the customer. However, this processing is affected by the change of sales support: firstly, the information to be processed is available on the website and is also the main basis of evaluation of service by the customer, in other words, when it comes to electronic shopping, multimedia information is the only form that the offer and its environment can take. Therefore, it is the only source of evaluation of service as opposed to the traditional sale where the evaluation has its roots in elements of various types as indicated by the dimensions of the SERVQUAL scale. In addition, a reliability assessment of the quality of service can be postulated, basing itself on the observation that the information processing on which it relies has become more rational thanks to the contributions of interactive tools the substituting electronic support; thus, the cognitive effort traditionally provided by the customer which can lead to a heuristic and even emotional information processing.

Finally, the assessment of risk to the customer after a purchase of service is, in turn, more stiffened when it comes to electronic service, because the cyber-client becomes more suspicious and more demanding because of the intangibility of the service, on the one hand, and the virtual environment of the offer, on the other: And that, primarily at the level of data privacy, security of payment tools and intelligibility of the application via the website service.

\section{Managerial Implications}

The incompatibility of many Web sites of service with the expectations of ecustomers shows a lack of mastery of the service in terms of issues and consequences related to the integration of electronic distribution channels in the range of supply and, particularly,in the management of electronic service quality: It is in this context that the managerial contributions of this analytical work can be defined. 
In fact, the understanding and the change of control of the bases for assessing the quality of service by the customer on this channel is a prerequisite for successful management of electronic quality and, therefore, a satisfaction of the e-customer's expectations. Thus, the manager should enhance his service offering depending on changes in the dimensions of quality assessment of that offer by the consumer.

In a more pragmatic way, the provider benefits the customer with maximum accessibility to the service through the medium of electronic sales; however, some effects that follow may go against the guarantee of quality electronic service at least equivalent to the traditional one, if not better. Note that the question of stabilizing the level of service quality does not arise for the manager except if he proposes an electronic distribution channel complementary to the traditional one, which makes it a reference channel in the field of the perception of the level of the quality of service delivered. By cons, taking into account the electronic channel independently of the other would abolish the problem of fluctuation in the level of quality because the service is provided by the machine via a website and therefore it is more standardized. In addition, the manager should make up for the dehumanization of the relationship, firstly, with a degree of personalization on the website allowing the client a free adaptation to the content that meets the very diverse needs in nature and intelligibility, and secondly, by maintaining the remote relationship through the possibility for the customer to contact the service via the website and the satisfactory reactivity of the latter compared to the demands of the customer. In addition, on the service website, the customer bases his assessment of quality in a virtual retail space, which means for the manager a transposition work from real and tangible features into virtual and electronic ones. This work is far from being simple because it must guarantee the same style and character of the physical retail space, on the one hand, and allow finding the same brand attributes (including the graphics, color ...), on the other hand, to prevent the client from feeling estranged in relation to the service provider. To do this, the manager has different tools that he should operate in this direction, including website design and graphic style used (colors, images, graphics, animation ...) that reflect the brand personality and the atmosphere of the physical retail space into the virtual one. Precisely, this virtual space grants the client, in another aspect, a margin of freedom of purchase and consumption of service so broad that it limits the room for control of the provider in the space of the sale and its conditions (an integral part of the assessment of quality of service by the customer), a finding that requires the provider to find the right balance between these two margins. In addition, in an electronic environment, the claimant often deals with more demanding customers and therefore more severe in his judgments than that accustomed to a traditional context. Indeed, the Internet client performs a streamlined processing of information through interactive tools that make his decision on quality more reliable and fair in comparison with the client who performs the same operation using only his cognitive abilities. Faced with this situation, the manager should ensure the quantity and quality of information appropriate to the site by type of service. On the other hand, the "stiffening" of the quality assessment by the customer is also palpable in the perception of incurred risk following a purchase of an electronic service. This implies, for the manager, an effort of rigor and additional credit in the electronic sale with respect to the traditional one, particularly through the implementation of policies and programs for secure payments and protection of personal data of which the customer must be aware through effective communication.

\section{Conclusion and Future Avenues of Research}

The analytical work undertaken in this paper highlights the impact of media technology in the supply of service via a website on the perception of service quality. Thus, the consumer's usual basis of judgment is either adapted or supplemented by a new one, or even 
completely abolished. In practice, this transformation compels the service provider to contain the fallout referring to the service offer and respond accordingly to ensure a consistent and optimal level of quality for the customer himself by alternating the use of traditional sales support and the electronic one.

In addition, we intend to draw the readers' attention to the fact that the study of the electronic form of the offer should be tied to more traditional ones, which urges us to suggest that it is facing the possible interactions that can operate between the two forms of service offering and the impact of these interactions on consumer perceptions. In addition, this study highlights the concepts that have not been so far considered in the measurement scales of perceived quality of electronic service but not without relevance, in particular, the degree of interactivity of the website that can be studied from the angle of the cyberconsumer, where it forms a possible basis for its assessment of electronic service quality and consequently its perception of the latter. Hence, the interest that researchers should bear to focus on the concept of interactivity as a plausible dimension of the perceived quality of electronic service, especially as these dimensions and their number still raises no consensus among the authors in service marketing.

\section{References}

Asubonteng, P., McCleary, K. J. \& Swan, J. E. (1996). "SERVQUAL Revisited: A Critical Review of Service Quality," The Journal of Services Marketing, 10, 6, 62-81.

Barnes, S. J. \& Vidgen, R. T. (2003). 'An Integrative Approach to the Assessment of E-Commerce Quality,' Journal of electronic commerce research, 3, 3, 114-127.

Bressolles, G. (2006). "La Qualité de Service Électronique: Netqu@l Proposition d'une Échelle de Mesure Appliquée aux Sites Marchands et Effets Modérateurs," Recherches et Applications en Marketing, 21, 3, 19-45.
Bressolles, G. \& Durrieu, F. (2006). 'Une Typologie Prédictive de la Satisfaction en Ligne par la Qualité de Service Électronique,' Actes du22ème Congrès international de l'association Française du marketing, Nantes.

Cases, A. S. (2002). 'Effets des Combinaisons de Réducteurs sur le Risque Perçu dans le Contexte de l'achat Électronique sur Internet,' Actes du 18ème Congrès International de l'Association Française de Marketing, Lille.

Dabholkar, P. A. (2000). Technology in Service Delivery: Implications for Selfservice and Service Support, Handbook of Services Marketing and Management, New York, Sage publication, 103-10.

Dabholkar, P. A., Shepherd, C. D. \& Thorpe, D. I. (2000). "A Comprehensive Framework for Service Quality: An Investigation of Critical Conceptual and Measurement Issues through a Longitudinal Study," Journal of Retailing, 76, 2, 169-173.

Eiglier, P. \& Langeard, E. (1987). 'Servuction: le Marketing des Services,' Stratégie et Management, Paris, Mc GrawHill.

Filser, M. (1996). "Vers une Consommation plus Affective?," Revue Française de Gestion, 110, 90-99.

Grönroos, C. (1982). Strategic Management and Marketing in the Service Sector, Helsingfors: Swedish School of Economics and Racine, Administration.

Oliver, R. L. (1977). 'The Effects of Expectations and Disconfirmation on PostExposure Product Evaluations,' Journal of Applied Psychology, 246-250.

Parasuraman, A., Berry, L. \& Zeithaml, V. (1985). "A Conceptual Model of Service Quality and its Implications for Future Research," Journal of Marketing, 49, 41-50.

Parasuman, A., Zeithaml, V. A. \& Berry, L. (1988). 'Servqual: A Multiple-Item Scale for Measuring Consumer Perceptions of 
Service Quality,' Journal of Retailing, 64, 1, 12-40.

Parasuraman, A., Zeithaml, V. A. \& Malhotra, A. (2005). "E-S-QUAL: A MultipleItem Scale for Assessing Electronic Service Quality," Journal of Service Research, 7, 3, 213-233.

Philippe, J. (1994). 'La Qualité dans les Rencontres de Service en Présence de l'ordinateur,' Actes du 2ème séminaire de recherche en management des activités de service, IAE d'Aix en Provence.

Rust, R. T. \& Oliver, R. L. (1994). Service Quality: New Directions in Theory and Practice, New York, Sage Publications.

Sabadie, W. \& Vernette, E. (2003). "La Servuction on Line: Points Communs et Spécificités Face à la Servuction Traditionnelle," Actes de la 2ème Journée AFM sur le e-marketing, Nantes.

Tournois, N. (1999). 'Le Marketing bancaire face aux nouvelles technologies,' Paris, Masson.
Volle, P. (2000). "Du Marketing des Points de Vente à Celui des Sites Marchands: Spécificités, Opportunités et Questions de Recherche," Revue Française du Marketing, 177-178, 2-3, 83-101.

Wolfinbarger, M. \& Gilly, M. C. (2003). "eTailQ: Dimensionalizing, Measuring and Predicting Etail Quality," Journal of Retailing, 79, 3, 183-198.

Yoo, B. \& Donthu, N. (2001). 'Developing a Scale to Measure the Perceived Quality of Internet Shopping Sites (SITEQUAL),' Quarterly Journal of Electronic Commerce, 2, 1,31-47.

Zeithaml, V., Parasuraman, A. \& Malhotra, A. (2002). "Service Quality Delivery through Websites, a Critical Review of Extant Knowledge Marketing to and Serving Customers through the Internet: Conceptual Frameworks, Practical Insights, and Research Directions," Journal of the Academy Marketing Science, 30, 4, 135-142. 
Appendix 1:

Table 1- Summary of Main Scales for Measuring the Electronic Perceived Quality of

Service

\begin{tabular}{|c|c|c|c|c|}
\hline Scale & Items nbr & Dimensions & Dependant variables & Sample \\
\hline \multirow{4}{*}{$\begin{array}{c}\text { NetQual } \\
\text { (Bressolles \& } \\
\text { Durrieu, 2006) }\end{array}$} & \multirow[t]{4}{*}{13} & Design & Satisfaction & \multirow{4}{*}{$\begin{array}{l}803 \text { customers of a travel } \\
\text { agency that booked or } \\
\text { requested a quote online }\end{array}$} \\
\hline & & Browsing & & \\
\hline & & Information & & \\
\hline & & Security & & \\
\hline \multirow{4}{*}{$\begin{array}{c}\text { e-S-Qual } \\
\text { (Parasuraman \& } \\
\text { al, 2005) }\end{array}$} & \multirow[t]{4}{*}{22} & Efficiency & Perceived value & \multirow{7}{*}{$\begin{array}{l}653 \text { users of the Website } \\
\text { amazon.com et } 253 \text { users of the } \\
\text { Website walmart.com having } \\
\text { made?? at least three purchases } \\
\text { over the last three months. }\end{array}$} \\
\hline & & $\begin{array}{l}\text { Compliance to } \\
\text { commitments }\end{array}$ & Intention for loyalty & \\
\hline & & $\begin{array}{l}\text { Availability of the } \\
\text { Website system }\end{array}$ & & \\
\hline & & Respect for privacy & & \\
\hline \multirow{3}{*}{ e-RecS-Qual } & \multirow[t]{3}{*}{11} & Reactivity & & \\
\hline & & Compensation & & \\
\hline & & Contact & & \\
\hline \multirow{4}{*}{$\begin{array}{c}\text { eTailQ } \\
\text { Wolfinbarger \& } \\
\text { Gilly (2003) }\end{array}$} & \multirow[t]{4}{*}{14} & \begin{tabular}{|l|} 
Design \\
\end{tabular} & Satisfaction & \multirow{4}{*}{$\begin{array}{l}1013 \text { respondent from a } \\
\text { costumer panel. }\end{array}$} \\
\hline & & Client service & Attitude toward the & \\
\hline & & $\begin{array}{l}\text { Reliability / } \\
\text { Compliance to } \\
\text { commitments } \\
\end{array}$ & Intention for loyalty & \\
\hline & & $\begin{array}{l}\text { Security and respect } \\
\text { for privacy }\end{array}$ & $\begin{array}{l}\text { Overall quality of the } \\
\text { service }\end{array}$ & \\
\hline \multirow{3}{*}{$\begin{array}{c}\text { WEBQUAL } \\
\text { Barnes \& Vidgen } \\
\quad(2003)\end{array}$} & \multirow[t]{3}{*}{22} & $\begin{array}{l}\text { Quality of } \\
\text { informations on the } \\
\text { Website }\end{array}$ & \multirow[t]{3}{*}{ 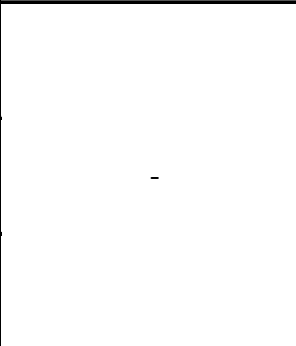 } & \multirow[t]{3}{*}{$\begin{array}{l}380 \text { student responding to a } \\
\text { questionnaire about } 3 \text { online } \\
\text { librairies. }\end{array}$} \\
\hline & & $\begin{array}{l}\text { Quality of the } \\
\text { l'interactivity (trust, } \\
\text { empathy) }\end{array}$ & & \\
\hline & & $\begin{array}{l}\text { Usability of the } \\
\text { Website (usability, } \\
\text { design) }\end{array}$ & & \\
\hline \multirow{6}{*}{$\begin{array}{l}\text { SITEQUAL Yoo } \\
\text { \& Donthu (2001) }\end{array}$} & \multirow[t]{6}{*}{9} & Ergonomy & Overall quality of the & \multirow{6}{*}{$\begin{array}{l}94 \text { student visiting and inter- } \\
\text { reacting with } 3 \text { online salling } \\
\text { websites. }\end{array}$} \\
\hline & & Design & Attitude toward the & \\
\hline & & $\begin{array}{l}\text { Quickness of the } \\
\text { process }\end{array}$ & Loyalty to the Website & \\
\hline & & Security & «Capital » of the & \\
\hline & & & Intention of purchase & \\
\hline & & & Intention of revisit & \\
\hline
\end{tabular}

